\title{
PENSANDO A PRÁXIS CRISTÃ CONTEMPORÂNEA: CONTRIBUTOS DE MAURICE BLONDEL
}

\section{THINKING ABOUT CONTEMPORARY CHRISTIAN PRAXIS: MAURICE BLONDEL'S CONTRIBUTIONS}

\author{
Marcus Aurélio Alves Mareano*
}

\begin{abstract}
RESUMO
Este artigo reflete a respeito da ação dos cristãos na contemporaneidade, considerando as contribuições do pensamento de Maurice Blondel. Primeiramente, observamos as transformações ocorridas na Idade Moderna e suas influências para a religião cristã. No momento presente, considerado por muitos teóricos como Pós-modernidade, o que era valioso na modernidade passa a ser questionado, e outras aceleradas mudanças socioculturais acontecem, gerando novos desafios para a fé em Cristo. Então, a partir da vida de Jesus, compreendemos a ação como conteúdo essencial para ser cristão na contemporaneidade. Assim, apresentamos o pensamento fenomenológico de Blondel como sustentação filosófica para propor a práxis cristã hodierna como maneira autêntica da vivência dos ensinamentos de Jesus. Blondel oferece contributos para que a experiência cristã não se torne mera teoria ou lembrança saudosa de um passado de dominação cultural. Ser cristão implica atuar eficazmente no tempo presente, tornando a fé um elemento indispensável para o ser humano.
\end{abstract}

PALAVRAS-CHAVE: Cristianismo. Pós-modernidade. Blondel. Ética cristã.

\section{ABSTRACT}

The article reflects on the action of Christians today considering the contributions of Maurice Blondel's thought. First, we observe the transformations that occurred in the Modern Age and their influences for the Christian religion. At the present moment, considered by many theorists as Postmodernity, what was valuable in modern times comes to be questioned and other accelerated socio-cultural changes are taking place, generating new challenges for faith in Christ. Therefore, through the life of Jesus, we understand action as an essential content to be a Christian in contemporaneity. Thus, we present Blondel's phenomenological thinking as a philosophical support to propose today's Christian praxis as an authentic way of living the teachings of Jesus. Blondel offers contributions so that the Christian experience does not become mere theory or longing memory of a past of cultural domination. Being a Christian implies acting effectively in the present time, making faith an indispensable element for human beings.

KEYWORDS: Christianity. Postmodernity. Blondel. Christian ethic.

\footnotetext{
* Mestre em Teologia e doutorado em Teologia pela Faculdade Jesuíta de Filosofia e Teologia. E-mail: marcusmareano@gmail.com.
} 


\section{INTRODUÇÃO}

O mundo atual, de rápidas transformações socioculturais, afeta o cristianismo e intima a Filosofia, a Teologia e outros saberes para refletir o valor da fé cristã na contemporaneidade.

Embora muitos insistam em pensar a partir dos parâmetros do século passado (ou de tempos anteriores), os desafios hodiernos diferem dos de outras épocas e nos interpelam para novas respostas. Uma sensibilidade pelo que se passa, uma observação às novidades ressurgentes e uma tentativa de real diálogo nos colocam sem respostas acabadas e na busca por pensamentos passados que nos inspirem para o presente.

Nesse sentido, este texto contribui com a reflexão sobre o cristianismo na atualidade, especialmente sua práxis, a partir de tópicos desenvolvidos por Maurice Blondel, a fim de subsidiar novos horizontes possíveis.

Partiremos da contextualização histórica da religião cristã desenvolvendo dois tópicos: a herança moderna para a religião cristã e o embate com a pós-modernidade. Uma percepção dos valores precedentes, suas características e seus efeitos colaboram com uma análise mais amadurecida do tempo e do espaço a partir da qual e para a qual nos expressamos, pois:

\footnotetext{
O falar cristão de Deus não poderá jamais ser proposto sem de algum modo se situar em relação ao mundo ao qual se dirige: se não fizesse esse esforço não passaria de ulterior forma de silêncio da Palavra. Motivando seu sentido diante dos contextos em que ecoa, a palavra cristã aprende a linguagem dos homens, fala as palavras do tempo, a fim de que nelas se torne presente a perene novidade de mensagem. (FORTE, 2003, p. 80).
}

Em seguida, proporemos a práxis como a contribuição mais importante dos cristãos para a sociedade. A exemplo do próprio líder, Jesus Cristo, que deixou uma prática de vida mais do que um conjunto de normas, as pessoas que o seguem devem se importar em praticar seus ensinamentos com sinceridade. Os tempos de uma fé por causa de instituições parecem ter passado, e a experiência e a vivência do que se crê valem mais do que os discursos.

Finalmente, consideraremos a Filosofia de Blondel como um valioso subsídio para a questão aqui abordada. $\mathrm{O}$ autor desenvolve uma Metafísica para a ação humana, que podemos assimilá-la para o agir dos cristãos. Ser é agir, e suas propostas contribuem para tal finalidade do ser humano no mundo. 


\section{A HERANÇA MODERNA PARA A RELIGIÃo CRISTÃ}

É sabido que a religião cristã vem passando por profundas transformações desde o século XVI. Não cabe aqui abordar o Renascimento ou mesmo o período denominado de Baixa Idade Média. Essas épocas já delineavam um novo rumo para o Ocidente e para o pensamento cristão, mas ainda estavam profundamente alicerçados na Tradição e na Escritura. O ponto nevrálgico que marca densamente uma época chegando até aos dias atuais é a Modernidade. Independentemente da discussão sobre moderno ou pós-moderno, tal fase histórica foi o ponto mais marcante do pensamento ocidental, tendo consequências irreversíveis para o cristianismo. Nos parágrafos seguintes serão abordados brevemente os impactos desse período, tendo como pano de fundo a reflexão ética. Esse corte é necessário para delimitar o assunto e não perder o foco principal proposto neste artigo.

É difícil sustentar que a maioria dos filósofos da modernidade não fosse cristã. Até mesmo Kant, um dos filósofos mais proeminentes desse período, faz filosofia tendo como horizonte o Deus cristão. Todavia, isso não significa que o pensamento filosófico simplesmente se apropriou das ideias cristãs e as enquadrou no campo filosófico. O que ocorre é uma acentuada ruptura entre religião e moral (FERRY, 2012, p. 81).

No século XVII, a metafísica ainda entende o ser humano sob a égide do Deus criador e salvador. Deus é o "alfa e ômega" e, por isso, a ação individual deve se ajustar ao Ser transcendente. Com efeito, praticar a moral é agir segundo os mandamentos de Deus. O homem é entendido como ser pecador, mas ao mesmo tempo dotado de graça divina para resgatá-lo do pecado. É preciso seguir os mandamentos até o fim da vida e, após superar esse vale de lágrimas, herdar o Reino dos Céus.

Desse modo, Deus é o fundamento, a pedra de toque para que a comunidade e cada pessoa tenham parâmetros para uma vida segundo a moralidade. O filósofo francês Luc Ferry (2012, p. 81-82) argumenta: "Essa perspectiva, na qual Deus vem lógica, moral e metafisicamente antes do homem, ainda se harmoniza com o que podemos chamar de ‘teológico-ético', ou seja, a fundação da moral sobre a religião.”

Kant é um dos primeiros filósofos modernos a tentar fundamentar filosoficamente uma moral que independa da religião. Ele estava convencido de que o homem deve estabelecer para si mesmo uma vida sob a luz da razão: "Esclarecimento [Aufklärung] é a saída do homem de sua menoridade, da qual ele próprio é culpado. A menoridade é a incapacidade de 
fazer uso de seu próprio entendimento sem a direção de outro indivíduo.” (KANT, 2013, p. $63)$.

Esse é o processo de autonomia tão caro ao filósofo e à própria modernidade e que passa a assumir um papel cada vez mais primário no pensamento moral. Obviamente, a reflexão da moral cristã continuou a ter enorme peso, mas passa a dividir terreno com uma ética secularizada. Nesse aspecto, há uma inversão de perspectiva pois Deus torna-se aos poucos uma ideia da razão pura e conduz a uma profunda mudança na reflexão filosóficoteológica (HÖFFE, 2005, p. 160).

A filosofia transcendental de Kant repropõe o problema da razão clássica e, por consequência, propõe um novo fundamento para o agir humano (HABERMAS, 1989, p. 18). Segundo Luc Ferry (2012, p. 81), esse novo modo de proceder decreta o fim do teológicoético, ou seja, a tradição cristã não vem antes do homem, mas depois dele caso ela esteja em acordo com a razão. A partir do pensamento moderno, sob a virada paradigmática do pensamento filosófico de Kant, o ser humano é concebido em sua racionalidade e, sobretudo, em sua liberdade que lhe confere dignidade e estabelece os princípios do respeito ao outro como simples dever moral e não mais por medo de um castigo posterior (KANT, 2016, p. 17). Luc Ferry (2012, p. 83) resume da seguinte forma o novo pensamento moderno a respeito da ética cristã:

\begin{abstract}
Sem desaparecer, o conteúdo da teologia cristã não vem mais antes da ética, para fundá-la em verdade, mas depois dela, para dar-lhe um sentido. O homem já não pode recorrer a Deus para compreender que deve respeitar o outro, tratá-lo como fim, e não apenas como meio. Desse modo, o ateísmo e a moral podem ser reconciliados. Mas a referência ao divino, a essa ideia de um Deus do qual Lévinas, fiel a essa tradição das Luzes, dirá que "vem a nosso espírito", tampouco desvanece. Ao contrário, ela subsiste por razões fundamentais. Por assim dizer, vem conferir um sentido ao fato de respeitar a lei, acrescentar a esperança ao dever, o amor ao respeito, o elemento cristão ao elemento judaico.
\end{abstract}

É importante ressaltar que a modernidade não está circunscrita ao pensamento de Kant, todavia ele é a culminância de um movimento que, desde os últimos séculos da Idade Média, consolidava-se cada vez mais (KOYRÉ, 1991, p. 22-23). A descoberta do "novo mundo", a reforma protestante, o desenvolvimento das ciências, o surgimento dos Estados Nacionais, foram fatores, dentre tantos outros, que conduziram a esse novo paradigma. $\mathrm{O}$ que se estabelece desde então é o teísmo como única possibilidade para conciliar a fé e a razão. Não é Deus que se antecipa ao homem e sim o contrário. Posto tal desafio, uma autêntica reflexão da fé cristã leva em consideração esse movimento profundo da tradição ocidental. 
As consequências dessa enorme efervescência chegam aos dias de hoje sob a forma do materialismo, consumismo, individualismo, crise ecológica, etc. Vive-se o tempo do efêmero, da velocidade, da falta de forma, do protagonismo de cada sujeito. A modernidade ainda tentou alçar um grande projeto marcado pela solidez, mas o que se estabelece hoje é um tempo de grande fluidez. As relações são marcadas pelo número de amigos nas redes sociais, ou pelo número de "curtidas" recebidas.

Pela primeira vez na história, o ser humano tem a capacidade de impor a si mesmo e à natureza um rompimento de seus limites pré-estabelecidos. As armas nucleares, a inteligência artificial e a engenharia genética podem criar um ser humano completamente novo. Os animais passam por modificações genéticas profundas, e ainda não se sabe quais serão as consequências dessas intervenções. A modernidade, por meio da ciência, cria um paradoxo: ela ao mesmo tempo liberta o homem de seus antigos medos, mas lhe impõe outros, como por exemplo, o perigo de romper os limites naturais sem uma reflexão consistente sobre tais avanços.

Mesmo o Deus cristão é "customizado", ou seja, Ele deve servir e ser fonte de plena alegria; caso saia dessas condições deve ser automaticamente descartado. Portanto, o processo iniciado pela modernidade é atomizado e se adapta ao indivíduo.

Essas consequências não são a proclamação do fim do mundo. Pelo contrário, esses desafios são sinais de que o ser humano está sempre em movimento, que quer modificar o que está estabelecido; enfim, deseja sempre alargar suas fronteiras. Diante disso, a religião cristã é convidada a repensar sua caminhada a fim de propor para si mesma e para seu tempo um novo jeito de viver a revelação cristã.

O contexto atual é propício para articular o conhecimento humano e a revelação cristã, partindo-se do princípio de que essas duas dimensões não são dicotômicas, mas podem se conciliar respeitando o campo específico de cada uma. No início da era cristã, os primeiros padres da Igreja logo perceberam que não era necessário declarar guerra à cultura de seu tempo. Eles fizeram uma bela síntese entre Tradição cristã e o pensamento helênico. Hoje, apesar de as questões serem diferentes, o cristianismo pode manter fecundo diálogo com o mundo contemporâneo, sem perder sua essência. As páginas seguintes abordam essa necessidade sob o auxílio do filósofo cristão Maurice Blondel. 


\title{
2 O EMBATE COM A PÓS-MODERNIDADE
}

Desde o início deste novo milênio, nós nos situamos em tempos de rápidas mudanças socioculturais. O que era exato, firme, consistente agora passa por um estado de liquefação. A pós-modernidade vem se consolidando como novo tempo.

Situamo-nos nesse momento incógnito da nossa história. As realidades estão dissolvidas e misturadas, por isso a metáfora da "fluidez", conforme o uso difundido por Zygmunt Bauman (2001, p. 7-10, passim), que prefere denominar a contemporaneidade como modernidade líquida a aderir ao usual termo "pós-modernidade". Nós recebemos uma herança de um processo de secularização desde a modernidade. O pensamento atual considera "caducas" e "superadas" as questões modernas (por exemplo: verdade absoluta, moral universal, supremacia da razão) e cinde com a tradição. O passado não importa, e o futuro não interessa. O que existe é o presente. Por essa razão, um tempo de instabilidade, crises (moral, fé, economia, política, meio ambiente, religião) e um relativismo pertinente, como observa Harvey (1992, p. 293):

\begin{abstract}
A experiência do tempo e do espaço se transformou, a confiança na associação entre juízos científicos e morais ruiu, a estética trinfou sobre a ética como foco primário de preocupação intelectual e social, as imagens dominaram as narrativas, a efemeridade e fragmentação assumiram precedência sobre verdades eternas e sobre a política unificada e as explicações deixaram o âmbito dos fundamentos materiais e político-econômicos e passaram para a consideração de práticas políticas e culturais autônomas.
\end{abstract}

Do ponto de vista das religiões, nós passamos de tempos da "morte de Deus" para uma "revanche religiosa":

\footnotetext{
Ouve-se falar, cada vez mais frequentemente, de um regresso do 'religioso' ou do 'sagrado'. E é já costume caracterizar a nossa época, precisamente, por esse regresso, o que a tornaria uma época de atitude pós-moderna, isto é, superadora de uma correspondente atitude moderna, que se diz por sua natureza adversa ao religioso e ao sagrado. (DUQUE, 2003, p. 163).
}

A proliferação das crenças responde à necessidade de recompor, a partir do indivíduo e de seus problemas, algo do sentido perdido. No final do milênio passado, havia uma procura pela religião por medos diversos do fim das coisas. No momento, predomina uma sede religiosa por uma busca de sentido existencial. A religião na contemporaneidade se caracteriza, entre outras coisas, pela difusão de crenças individualistas, uma reconsideração 
institucional da religiosidade e uma nova religiosidade flutuante de elaborações sincréticas (HERVIER-LÉGER, 2008, p. 20-25). Assistimos a um processo de "desregulação" das religiões.

A cultura ocidental se fundamenta também sobre a religião cristã. Estatisticamente, os cristãos ainda são maioria em muitos países. Muitos vivem sem religião, mas de "sensibilidade" ou de "tradição" católica. Há a diminuição da fronteira entre os católicos e os não católicos, entre os religiosos e os não religiosos. Há um crescimento dos chamados “crentes não praticantes"; afirmam ser cristãos, mas não têm relação com as instituições. Uma crise de fé se instaura no nosso momento sociocultural devido ao desafio da transmissão da fé (HERVIER-LÉGER, 2008, p. 58).

As novas gerações se opõem às antigas. Há lacunas diferentes e enormes entre uma geração e outra, que representam verdadeiras rupturas culturais. A crença escapa ao controle das grandes igrejas, das instituições religiosas e também dos pais. As instituições não predominam sobre o indivíduo. A descrição da religião se organiza a partir da tendência geral à individualização e à subjetividade das crenças. Os indivíduos fazem valer sua liberdade de escolha, cada qual retendo para si as práticas e as crenças que lhe convêm.

O indivíduo atual deseja uma experiência pessoal que corresponda aos seus anseios profundos e lhe forneça consolo e sentido de existência perene para sua vida. Todos se perguntam: o que sou eu? Por que estou aqui nesta existência? O que haverá após esse tempo de vida? Muitos saberes se esforçam para respostas, inclusive a religião. Antes, ela se apresentava com um núcleo a ser crido e aceito pelo fiel. Agora, ela chega como resposta às necessidades subjetivas e demandas a serem satisfeitas. Comenta a socióloga Danièle HervierLéger (2008, p. 143):

\footnotetext{
Não se trata de descobrir e aderir a uma verdade existente fora de si, mas de experimentar - cada um por si - sua própria verdade. Nenhuma autoridade pode, em questão espiritual, definir qualquer ortodoxia ou ortopraxia impondo-a do exterior ao indivíduo. O objetivo buscado é o aperfeiçoamento de si, aperfeiçoamento que não diz respeito à realização moral do indivíduo, mas ao seu acesso a um estágio superior de ser. Este autoaperfeiçoamento é acessível através de práticas psicocorporais que se servem de variadas técnicas oferecidas pelas instituições espirituais e místicas.
}

Portanto, a proposta cristã hoje não pode ser tida como óbvia. Ela deve sempre ser proclamada de novas maneiras a provocar os benefícios no ser humano, como afirma o Papa Francisco (2013, p. 7): “A alegria do Evangelho enche o coração e a vida inteira daqueles que 
se encontram com Jesus. Quantos se deixam salvar por Ele são libertados do pecado, da tristeza, do vazio interior, do isolamento. Com Jesus Cristo, renasce sem cessar a alegria.”

\section{A PRÁXIS CRISTÃ}

Jesus nasceu em Belém, cresceu em Nazaré e exerceu parte de seu ministério nas cidades da Galileia (FREYNE, 1996, p. 15-34, passim). Morreu em Jerusalém. Esses dados históricos retratam um ser humano real.

Diversos relatos bíblicos apresentam como Jesus vivia. Ele se relacionava com as pessoas, participava das celebrações do seu povo (os judeus), ensinava nas sinagogas e gostava de refeições com diferentes famílias. Rapidamente, tornou-se admirado pelas multidões que acorriam a ele em busca de consolo e alento, queriam ser curadas, procuravam soluções para as diversas aflições por que passavam (PAGOLA, 2011). Em meio às atividades, ele elege alguns pescadores para segui-lo e, depois, forma-se um grupo de doze (nenhum notável na sociedade) que o conhece mais intimamente, aprende com ele e se compromete com aquela novidade (PAGOLA, 2011, p. 326 et seq.). Além desses homens, Jesus permitia a companhia e a amizade de mulheres (Lc 8,1-3) (PAGOLA, 2011, p. 259-262, passim).

Todas essas características não fazem Jesus muito distinto de grandes seres humanos da nossa história. No entanto, a mensagem que ele transmite, uma "boa notícia" (em grego: euaggelión), totalmente original, provoca uma mudança no curso da história universal.

Jesus anunciava que o Reino de Deus se aproximava, as pessoas deveriam converterse e acreditar no Evangelho (Mc 1,15). O reino de Deus não representava um reino como aquelas pessoas imaginavam (p. ex. Império Romano), mas o reinado (ação) de Deus entre pessoas, para as pessoas, por meio daquele homem Jesus.

Jesus agia na condição de Filho de Deus: perdoava os pecados (Mc 2,5); purificava os leprosos (Mc 1,40-41); interpretava a Lei judaica (Mt 5,20-48); chamava Deus de pai e ensinava seus seguidores a chamá-lo da mesma maneira (Mt 6,9); assumiu uma condição de servo e deu sentido à própria existência servindo aos outros (Lc 22,24-27; Jo 13,12-15), principalmente aos menos favorecidos (pobres, enfermos, prostitutas e publicanos).

Para sintetizar seus ensinamentos, Jesus disse: "amai a Deus sobre todas as coisas e ao próximo como a si mesmo" (Mt 12,29; Lv 19,18); e ainda: “Amai-vos uns aos outros como eu 
vos amei, nisso reconhecerão que vós sois meus discípulos se tiverdes amor uns aos outros" (Jo 13,34-35). Jesus expressa com sua existência uma ética e não um conjunto de normas, ele ensina com a prática, e suas ações eram ensinamentos. Suas palavras eram acompanhadas de gestos, e seus atos anunciavam uma mensagem de quem é divino.

Amar para Jesus não era apenas um sentimento ou uma emoção, mas era uma prática de vida, doação de si para o próximo, uma maneira de ser, isto é, uma ética. O amor consiste em perdoar a quem ofender (Mt 6,12; 18,21-22); não retribuir o mal feito com mal (Mt 5,3940); fazer primeiro o que queremos que os outros nos façam (Mt 7,12); orar por aqueles que perseguem e amar os inimigos (Mt 5,44); não condenar nem julgar (Mt 7,1); servir humildemente (Lc 17,10). Na existência humana de Jesus, vê-se a vivência do amor até o fim: "tendo amado os seus que estavam no mundo, amou-os até o fim" (Jo 13,1).

A passagem de Mt 25,31-46 retrata como deve proceder o cristão. Jesus convida: "Vinde benditos do meu Pai, recebei por herança o reino preparado para vós, pois tive fome e me deste de comer. Tive sede e me deste de beber. Era forasteiro e me acolheste. Estive nu e me vestiste, doente e me visitaste, preso e viestes ver-me". Lê-se no relato uma questão dos justos: "quando fizemos isso?" Jesus respondeu: Cada vez que o fizestes a um desses irmãos mais pequeninos, a mim o fizestes (v. 40). Em seguida, os injustos são destinados a uma condenação porque deixaram de exercer o que deveriam. O cristão encontra no semelhante uma representação de Cristo. Cada vez que se faz algo (ou se deixa de fazer), ao Cristo que se faz.

O cristianismo autenticamente vivido contribui para uma ética no século XXI e para um mundo melhor. Embora muito se tenha errado na história usando o nome de Deus, o mundo e as pessoas poderiam ser piores sem a fé em Cristo. Os seguidores de Cristo são responsáveis por incontáveis benefícios sociais no passado e no presente da história universal, quiçá no futuro.

Há uma séria tarefa no mundo dito pós-moderno destinada aos cristãos: viver o verdadeiro amor a exemplo do mestre. Jesus não amou apenas os do seu povo e da sua raça. Ele amou também os samaritanos (povo com quem os judeus não tinham boas relações), os publicanos (pecadores públicos com fama de ladrões), soldados romanos (centurião que pediu a cura da sua filha), Madalena, Zaqueu, Judas, Paulo, a mim e a você. Quem é o seu próximo hoje? Onde está teu irmão? 
Um excelente exemplo, nós lemos em um trecho da "Carta a Diogneto" (capítulos 56), um escrito do século II dC por um discípulo cristão para apresentar a fé cristã a Diogneto, um distinto no Império romano:

\begin{abstract}
Não se distinguem os cristãos dos demais, nem pela região, nem pela língua, nem pelos costumes. Não habitam cidades à parte, não empregam idioma diverso dos outros, não levam gênero de vida extraordinário. A doutrina que se propõem não foi excogitada solicitamente por homens curiosos. Não seguem opinião humana alguma, como vários outros fazem. Moram alguns em cidades gregas, outros em bárbaras, conforme a sorte de cada um; seguem costumes locais relativamente ao vestuário, à alimentação e ao restante estilo de viver, apresentando um estado de vida (político) admirável e, sem dúvida, paradoxal. Moram na própria pátria, mas como peregrinos. Enquanto cidadãos, de tudo participam, porém tudo suportam como estrangeiros. Toda terra estranha é pátria para eles e toda pátria, terra estranha. [...] amam a todos, e por todos são perseguidos. Desconhecidos, são condenados. São mortos e com isso se vivificam. (CARTA..., 1976, p. 22-23).
\end{abstract}

\title{
4 APORTES DA FILOSOFIA DE BLONDEL PARA A AÇÃO DOS CRISTÃOS
}

Maurice Blondel nasceu em 1861, morreu em 1949, e a maior parte de sua história pessoal se passou na França. Um cristão católico convicto que procurou dar inteligibilidade de sua fé no ambiente intelectual, hostil e pouco religioso no qual se inseria. Seu pensamento filosófico contribui para a reflexão teológica e nos ajuda a pensar o nosso momento presente.

Para Blondel, a Filosofia não deve ignorar a realidade de fé; ao contrário, deve se interessar pelo mistério e pelas questões de fé para tentar explicitá-las. Ambos saberes (Filosofia e Teologia) se preocupam com o sentido e o destino do ser humano e tentam responder a tais questões. Ele propõe uma reflexão que conduz à aceitação dos próprios limites da razão, com uma abertura ao dom sobrenatural (intellectus quaerens fidem), pois a razão aspira ao infinito, mas não o atinge, devendo reconhecer sua insuficiência e acolhê-lo como dom (BLONDEL, 1934, p. 370). Assim, Blondel elabora uma "Filosofia orante", compreendendo que a razão não alcança o objeto divino e se põe na espera para acolhida do dom desejado (RIVAS, 2012, p. 29-55, passim). O pensamento tem um limite, e essa insuficiência é a possibilidade de expansão.

Em sua reflexão, Blondel propõe uma maneira nova de pensar a Metafísica. Embora ele não tenha escrito um tratado, todo seu sistema filosófico expõe sua ideia acerca da Metafísica (RIVAS, 2012, p. 87-102, passim). Ela é considerada como a ciência do além, superior e interior ao ser humano. Ela se centra no absoluto e compreende-se a partir da ação dos seres. Para tanto, ele não parte de ideias abstratas, mas do concreto singular, no qual o 
universal subsiste. Dessa forma, a ação humana é o centro da filosofia e no qual ocorre o encontro entre o querer e a inteligência. Com isso, Blondel faz uma Metafísica como modo de viver e pensar, e supera a dicotomia entre teoria e ação, entre a razão pura e a razão prática, porque seu ponto de partida é a ação. Uma orientação teórica tem valor se incide na prática real; a práxis deve ser fidelidade ao que se experimenta por meio da fé. Por isso, as verdades de fé e as tensões escatológicas não são meras abstrações, mas implicações para as atitudes da vida presente.

A partir de sua obra principal (L'Action - 1893), Blondel sustenta que a ação é parte genuína dos seres humanos, por isso, objeto de compreensão racional por parte da filosofia. O objetivo da ação é a conquista do ser, que é presença, mistério e aspiração a uma plenitude não encontrada. Blondel divide o estudo da ação em duas partes: primeira, uma teoria da ação que visa especificar a possibilidade da Metafísica (função, sentido e valor da ação); na segunda parte, trata-se de dar crédito à prática, às ideias que nascem dela (RIVAS, 2012, p. 274-275). Blondel promove uma filosofia praticante, na qual o ser humano assiste ao desenvolvimento das tendências que nos conduzem à finalidade desejada e nele coopera. A ciência da ação tenta manifestar a originalidade do dinamismo intrínseco da ação pelo que a especulação esclarece e enriquece a prática (RIVAS, 2012, p. 276).

A ação deve ser toda do homem, mas como se fosse toda dependente da vontade de Deus, numa síntese entre as vontades humana e divina, na qual uma não pode nada sem a outra (BLONDEL, 1893, p. 385). A ação é o ponto de encontro e de cooperação e o lugar de comunhão entre o ser humano e sua destinação própria (Deus), em que o homem ascende à finalidade para a qual foi criado e o meio pelo qual se configura ao infinito que é o princípio e o fim da ação humana. A comunhão é a consumação da ação plenamente realizada pela participação na caridade, assumindo humildemente a condição de pedinte e aspirante, na docilidade, obediência e abnegação ao dom da graça.

A orientação e a finalidade da ação humana é Deus. Mesmo ela sendo múltipla e transitiva, ela anseia a unidade, que atrai e impulsiona a ação. O ser humano é livre pois age conforme sua orientação e finalidade. Assim, a filosofia blondeliana destaca a dialética da presença e de possessão, da invocação e da recepção. Em ambos os casos se manifesta a ineficácia da ação humana de dar-se ou de procurar-se por suas próprias forças. A acolhida ou a rejeição do dom superior que introduz na vida divina representa o drama de toda criação gemente. A abnegação adquire a possibilidade de um desenlace glorioso, não porque o agente faz tudo, mas porque espera tudo, e esperar para o cristão significa operar. A abnegação é 
docilidade e submissão à tendência e aspiração de comunhão, todo ato tende a ser comunhão. A vida em ato é o lugar da comunhão e da conexão universal tendendo a unificar-se sem jamais alcançar uma unidade estável.

"A forma blondeliana de abordar os problemas filosóficos, teológicos, sociais e políticos estará caracterizada sempre por aquela vontade de pensar a mobilidade, inquietude ou equilíbrio permanentemente instável que é a vida humana" (MORLANS, 2000, p. 261). Para Blondel, a reflexão deve atentar na prática em que a realidade está presente e atuante, impulsionando para a unidade, por meio da diversidade, e atraindo para a plenitude do fim último. Com isso, o filósofo nos ajuda a refletir o ser cristão, que significa também agir, na atualidade.

\section{CONSIDERAÇÕES FINAIS: SER-AGIR CRISTÃO NA ATUALIDADE}

Para nós, Blondel oferece aportes para pensar nosso desafiador tempo presente e nos instiga a uma prática mais consistente para que de fato os cristãos sejam reconhecidos como discípulos de Jesus pela prática do seu mandamento (Jo 15,12-17; 13,35).

Primeiramente, Blondel foi um cristão que não se esquivou de pensar a própria fé. No caso dele, de maneira filosófica, mas que contribuiu com o pensamento teológico. Da mesma forma, a partir das próprias ciências, os cristãos podem, com seriedade e afinco à metodologia particular de cada ciência, encontrar razões para crer e robustecer a fé com as ciências e outros saberes, como nos recorda o Magistério eclesial (JOÃO PAULO II, 1998, p. 25; FRANCISCO, 2013, p. 135). Para o diálogo na contemporaneidade, a fé cristã precisa cada vez mais dos instrumentos e conhecimentos adquiridos a fim de melhor servir à humanidade.

Para Blondel, teoria e prática, razão e fé, pensamento e ação não são dicotômicos, mas complementares e um necessário a outro, como também afirma o Papa Francisco (2013, p. 131). Portanto, nosso pensamento deve refletir uma atitude; a fé deve ser intelectiva, e os atos cotidianos consequentes do que se pensa, crê, espera e ama. Não podemos viver uma fé sem uma vivência efetiva, apenas baseada em normas, doutrinas ou num código de condutas. A fé é a vida de Cristo presente na vivência dos cristãos. Nossas ações devem testemunhar a fé que temos. Os cristãos de hoje, como os de todos os tempos, não podem se assustar com as complexas situações desafiantes, porém ousar com criatividade, e com convicção agir em nome daquele em quem colocamos nossa confiança. 
A esperança cristã de novos céus e nova terra $(2 \mathrm{Pd} 3,13)$ não consiste apenas na construção de uma sociedade sem males. Aguardamos mais do que coisas para essa realidade do aquém; nossos olhares se voltam para o alto, embora com os pés fixos neste chão (GESCHÉ, 2005, p. 91-102, passim). Temos já a realidade futura, mas ainda não plenamente. Somos seres aspirantes e ansiantes da plenitude definitiva, responsáveis pelo destino e sentido pessoais e itinerantes na expectativa do dom que vem e que nos impulsiona na busca da própria destinação. $\mathrm{O}$ ser humano atual acostumado com a liquidez do momento presente deve encontrar, por meio do testemunho cristão, a eternidade, a plenitude e o infinito que dilatam e orientam nossas ações para a meta na qual nossa liberdade se realiza (DELUMEAU, 2007).

Enfim, nossa postura diante da contemporaneidade não pode ser de assombro e ocultamento. O cristão deve se pôr em êxodo constante ao advento do dom do Reino vindouro (FRANCISCO, 2013, p. 19). Nosso êxodo deve ser também presente nas ações cotidianas e nas relações com o próximo, vivendo o amor que temos como herança de Deus para nós. A sociedade e a cultura anelam pela transcendência, pela luz que o cristão recebeu. Que nossos atos brilhem diante das pessoas, para que vejam e louvem aquele que buscam (Mt 5,16).

\section{REFERÊNCIAS}

BAUMAN, Zygmunt. Modernidade líquida. Rio de Janeiro: Jorge Zahar, 2001.

BÍBLIA de Jerusalém. São Paulo: Paulus, 2002.

BLONDEL, Maurice. L'Action: essai d'une science de la pratique et d'une critique de la vie. Paris, 1893.

BLONDEL, Maurice. La Pensée II: Les responsabilités de la pensée et la possibilite de son achèvement. Paris, 1934.

CARTA a Diogneto. Petrópolis: Vozes, 1976.

DELUMEAU, Jean. À espera da aurora: um cristianismo para o amanhã. São Paulo: Loyola, 2007.

FERRY, Luc. Kant: uma leitura das três críticas. 3. ed. Rio de Janeiro: Difel, 2012.

FORTE, Bruno. Para onde vai o Cristianismo? São Paulo: Loyola, 2003.

FRANCISCO, Papa. Evagelii gaudium: sobre o anúncio do Evangelho no mundo atual. São Paulo: Loyola, 2013. 
FREYNE, Sean. A Galileia, Jesus e os evangelhos: enfoques literários e investigações históricas. São Paulo: Loyola, 1996.

GESCHÉ, Adolphe. O sentido. São Paulo: Paulinas, 2005.

HABERMAS, Jürgen. Consciência moral e agir comunicativo. Rio de Janeiro: Tempo Brasileiro, 1989.

HARVEY, David. Condição pós-moderna. São Paulo: Loyola, 1992.

HERVIER-LÉGER, Danièle. O peregrino e o convertido: a religião em movimento. Petrópolis: Vozes, 2008.

HÖFFE, Otfried. Immanuel Kant. São Paulo: Martins Fontes 2005.

JOÃO PAULO II, Papa. Carta encíclica fides et ratio: sobre as relações entre fé e razão. 4. ed. São Paulo: Paulus, 1998.

KANT, Immanuel. Crítica da razão prática. Petrópolis: Vozes, 2016.

KANT, Immanuel. Resposta à pergunta: o que é "Esclarecimento". 9. ed. Petrópolis: Vozes. 2013.

KOYRÉ, Alexandre. Estudos de história do pensamento científico. 2. ed. Rio de Janeiro: Forense Universitária, 1991.

MORLANS, Xavier. Elements per a una interpretació teològica de la Història Contemporania, inspirada nn Maurice Blondel. Revista Catalana de Teologia, local, v. 25, n. 1, p. 257-273, 2000 .

PAGOLA, José Antonio. Jesus: aproximação histórica. 4. ed. Petrópolis: Vozes, 2011.

RIVAS, Eugenio. La escatología como comunión: una propuesta desde la perspectiva metafísica de Maurice Blondel. Roma: PUG, 2012. Tese de doutorado. 